\title{
The forehead flap: a valuable option in resource depleted environment
}

\author{
Rowland Agbara1, Benjamin Fomete ${ }^{2}$, Athanasius Chukwudi Obiadazie ${ }^{2}$, Kelvin Uchenna \\ Omeje $^{3}$, Olushola Ibiyinka Amole ${ }^{3}$ \\ ${ }^{1}$ Oral and Maxillofacial Surgery Unit, Dental and Maxillofacial Surgery Department, Jos University Teaching Hospital, Jos 930001, \\ Nigeria. \\ ${ }^{2}$ Oral and Maxillofacial Surgery Department, Ahmadu Bello University Teaching Hospital, Shika-Zaria 810222, Nigeria. \\ ${ }^{3}$ Oral and Maxillofacial Surgery Unit, Dental and Maxillofacial Surgery Department, Aminu Kano University Teaching Hospital, Kano \\ 700233, Nigeria. \\ Correspondence Author: Dr. Rowland Agbara, Oral and Maxillofacial Surgery Unit, Dental and Maxillofacial Surgery Department, Jos \\ University Teaching Hospital, Jos 930001, Nigeria. E-mail: row_prof@yahoo.com
}

\begin{abstract}
Aim: Reconstruction of orofacial soft tissue defect is often challenging and this is more difficult in resource challenged environment. This retrospective study highlights our experience with the use of forehead flap to overcome some of the challenges of orofacial reconstruction in a resource depleted environment. Methods: A 23-year retrospective analysis of all patients who had orofacial defect reconstruction using forehead flap in our department was undertaken. Information was sourced from patient's case notes and operating theatre records. Data was analyzed using Statistical Package for Social Sciences (SPSS) version 16 (SPSS Inc., Chicago, IL, USA) and Microsoft Excel 2007 (Microsoft, Redmond, WA, USA). Results: A total of 43 patients were managed within the period reviewed and consisted of $31(72.1 \%)$ males and $12(27.9 \%)$ females. Trauma $24(55.8 \%)$ accounted for most defect and the lip was the commonest site of defect. Complete forehead flap was used in 31 (72.1\%) of cases and when timing of defect repair is considered, delayed reconstruction was the preferred method. Postoperative complications was observed in $8(18.6 \%)$ patients and consisted of failed flap in $2(25.0 \%)$ patients, tumor recurrence in reconstructed site in $2(25.0 \%)$ patients and tumor occurrence in forehead flap donor site in $1(12.5 \%)$ patient. Conclusion: The forehead flap remains a reliable option in orofacial soft tissue defect reconstruction. It is easy to raise and can provide coverage for wide defects as far as the paramandibular and submandibular regions. Moreover, it does not require patient repositioning.
\end{abstract}

Key words:

Orofacial; soft tissue defect; forehead flap; delayed reconstruction

\section{INTRODUCTION}

Tissues in the orofacial region contribute significantly to the functional, aesthetic and psychological wellbeing of an individual. ${ }^{[1,2]}$ Similarly, individuals place a high value on facial

\begin{tabular}{|l|l|}
\hline \multicolumn{2}{|c|}{ Access this article online } \\
\hline Quick Response Code: & Website: \\
\hline & www.parjournal.net \\
\cline { 2 - 2 } & \\
\hline
\end{tabular}

aesthetics such that alterations in facial appearance may cause severe disability, psychological morbidity, and huge economic loss to the victim(s). ${ }^{[3]}$ Defects in the orofacial region may involve

This is an open access article distributed under the terms of the Creative Commons Attribution-NonCommercial-ShareAlike 3.0 License, which allows others to remix, tweak and build upon the work non-commercially, as long as the author is credited and the new creations are licensed under the identical terms.

For reprints contact: service@oaepublish.com

How to cite this article: Agbara $R$, Fomete $B$, Obiadazie AC, Omeje $\mathrm{KU}$, Amole OI. The forehead flap: a valuable option in resource depleted environment. Plast Aesthet Res 2016;3:115-20.

Received: 23-11-2015; Accepted: 08-04-2016 
soft tissues, hard tissues or a combination of both and may be congenital or acquired in origin. ${ }^{[4]}$ Congenital defects include cleft lip/palate, maxillary and mandibular hypoplasia. Acquired defects may result from trauma, surgery or infections. Generally, the main etiological factor in acquired orofacial defects varies from one environment to another.

Reconstruction of orofacial tissue defects may be undertaken as an immediate or delayed procedure. Traditionally, the reconstructive ladder approach has been advocated in soft tissue defect reconstruction and this allows a stepwise option from the simplest to the most complex procedures. These procedures are healing by secondary intention, primary closure, skin grafting and use of local, regional and free flaps techniques. However, recently the concept of reconstructive escalator or elevator has been advocated since reconstruction should be individualized to each patient and not based on a rigid approach..$^{[5,6]}$

Despite advances in soft tissue reconstruction using free flaps, pedicle flaps are still relevant in functional and aesthetic rehabilitation of patients. ${ }^{[7]}$ Free flaps provide enough volume of tissue for reconstruction; they are more resistant to radiation injury (which is important cancer patients requiring radiotherapy); allow for unrestricted flap repositioning, and achieve optimal reconstruction with resultant reduction in the cost and morbidity often associated with repeat surgeries due to failure of suboptimal reconstructions using locoregional flaps. ${ }^{[8]}$ However, use of free flaps is technique sensitive, involves prolong procedure, require extensive postoperative monitoring, may be relatively contraindicated in some patients with co-morbid conditions, and there may be aesthetic problems such as flap bulkiness, colour and texture mismatch. ${ }^{[9,10]}$ Locoregional flaps have reduced vulnerability to infection and thrombosis; they are much easier to raise and transfer when compared to free flaps, and usually provide excellent colour match. Limited reach of locoregional flaps, difficulty in achieving three-dimensional reconstruction or cover extensive tissue defects, and occasional need for multistage procedure are some of its limitations. ${ }^{[1]}$ Moreover, locoregional flaps frequently have complications in irradiated fields and may require specific patient positioning to raise. ${ }^{[9]}$

In current practice, locoregional flaps are still important for head and neck reconstruction in environment where microvascular free tissue transfer is not feasible. In technologically developed environment, they are used as rescue flaps following free flap failure and in patients with relative contraindications for free flap transfer such as the presence of co-morbid medical conditions. ${ }^{[12]}$

The forehead region over the years has remained the best donor site for nasal reconstruction, having the advantage of textural, thickness and colour match. ${ }^{[13]}$ Different types of forehead flaps with axial or random pattern blood supply have been described. ${ }^{[14]}$ The aim of this study therefore is to review the use of forehead flap in orofacial reconstruction, highlighting our experience in the management of forty-three cases.

\section{METHODS}

All patients who had orofacial reconstruction using forehead flap at a regional teaching hospital from April 1991 to June 2014 were retrospectively studied. Information was sourced from patient's case notes and operating theatre register. Information retrieved included age, gender, indication for surgical reconstruction, type of forehead flap, duration of hospital stay and complications. All patients agree with this publication and use of photographs.

\section{Preoperative planning}

The superficial temporal artery was assessed preoperatively by palpatory method only. This involved the identification of its outline and feeling the strength of its pulsation. The position of other axial vessels of the forehead was planned based on established anatomical guidelines. Presence of significant scars along established axial vessels of the forehead which may indicate vascular compromise were also excluded. Patients for complete forehead flap raising were instructed to shave their hair but preserve the hairline.

\section{Surgical procedure}

Reconstruction was carried out as a two or three (if debulking is necessary) stage procedure involving initial flap raising and transfer, followed by flap division usually after a period of three weeks, and finally debulking of the reconstructed site. When complete forehead flap was raised, split thickness skin graft from the thigh was used to cover the flap donor site either intraoperatively or $24-48 \mathrm{~h}$ postoperatively (to reduce operating time or allow for adequate hemostasis) on the dental chair, secured with sutures and a pressure dressing applied on the forehead to prevent hematoma collection under the skin graft.

The critical aspect in successfully raising a complete forehead flap is the plane of dissection close to its base to avoid damage to the nutrient vessels. The key is to initially raise the flap supraperiosteally from one end of the forehead until the temporalis fascia is encountered on the contralateral side. Once the temporalis fascia is encountered on the contralateral side, dissection with scissors should follow a connective tissue plane above the fascia to preserve the nutrient vessels of the flap.

\section{Classification}

Forehead flap was classified as either complete (if the whole forehead tissue between hairline and supraorbital rim was mobilized from a point perpendicular to the lateral canthal region on one side to the corresponding point or beyond on the contralateral side) or partial (if only a part of the forehead tissue was mobilized), while timing of flap division was classified as early (less than 16 days), conventional (between 16-28 days) or delayed (greater than 28 days). Reconstruction was classified as immediate (if done within $24 \mathrm{~h}$ following defect formation) or delayed (if done after $24 \mathrm{~h}$ following defect formation), and two stage (initial flap raising and flap division later) or three stage (initial flap raising, flap division and secondary debulking of recipient site).

Data retrieved was analyzed using Statistical Package for Social Sciences (SPSS) version 16 and Microsoft Office Excel 2007. Findings from descriptive statistics were represented in the form of graphs, tables and charts. 


\begin{tabular}{ll}
\hline Table 1: Site of orofacial defect & \\
\hline Site & Frequency \\
\hline Lip & 15 \\
Nose & 13 \\
Cheek & 9 \\
Eyelid & 7 \\
Perimandibular/submandibular region & 3 \\
\hline
\end{tabular}

Table 2: Timing of forehead flap division in 19 patients

\begin{tabular}{ll}
\hline Time of flap division & Number of patients \\
\hline Less than 16 days & - \\
$16-28$ days & 8 \\
Greater than 28 days & 11 \\
\hline
\end{tabular}

Table 3: Complications noted following use of forehead flap

\begin{tabular}{ll}
\hline Complication & Frequency \\
\hline Total flap failure & 2 \\
Epidemolysis & 1 \\
Infection & 4 \\
Tumor recurrence in flap recipient site & 2 \\
Tumor occurrence in flap donor site & 1 \\
\hline
\end{tabular}

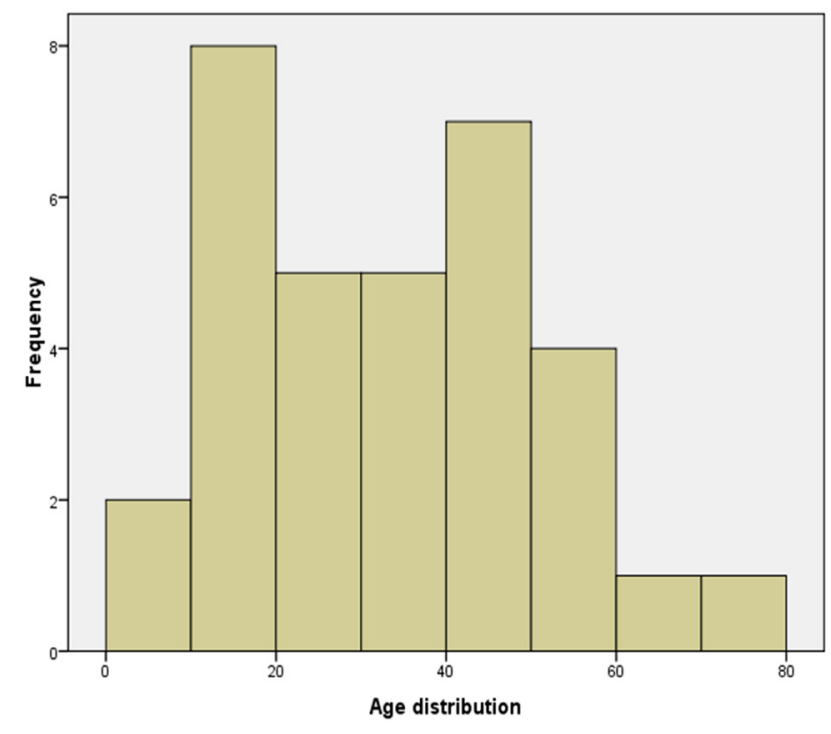

Figure 1: Age distribution

\section{RESULTS}

A total of 43 patients had orofacial reconstruction using forehead flap under general anesthesia within the period reviewed and this consisted of $31(72.1 \%)$ males and 12 (27.9\%) females, giving a male to female ratio of 2.6:1. Patients' ages ranged from 4 to 75 years [Figure 1] with a mean of $33.9 \pm 16.3$ years. The aetiology of soft tissue defect was trauma in 24 (55.8\%) cases, tumor resection in $13(30.2 \%)$ cases, and infection in $6(14.0 \%)$ cases [Figure 2]. Road traffic crashes accounted for 11 (45.8\%) of 24 cases of trauma associated soft tissue defects, while malignant tumor excision accounted for 11 (84.6\%) of 13 cases associated with tumor excision. All soft tissue defects arising from orofacial infection were as a result of cancrum oris. When site of defect is considered, the lip 15 (31.91\%) had the highest frequency [Table 1].

Complete forehead flap was used in 31 (72.1\%) of cases while

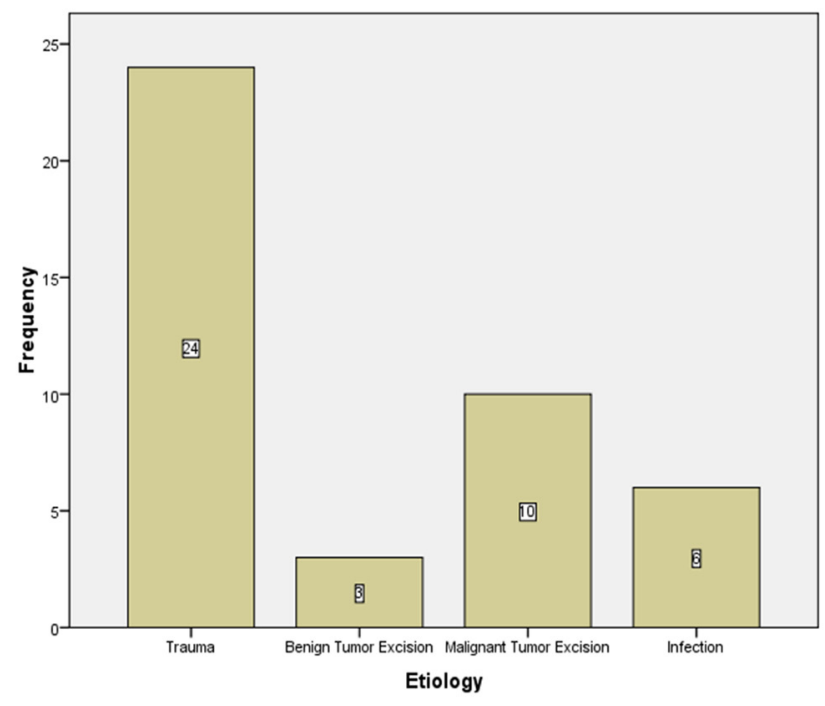

Figure 2: Etiology of orofacial defect

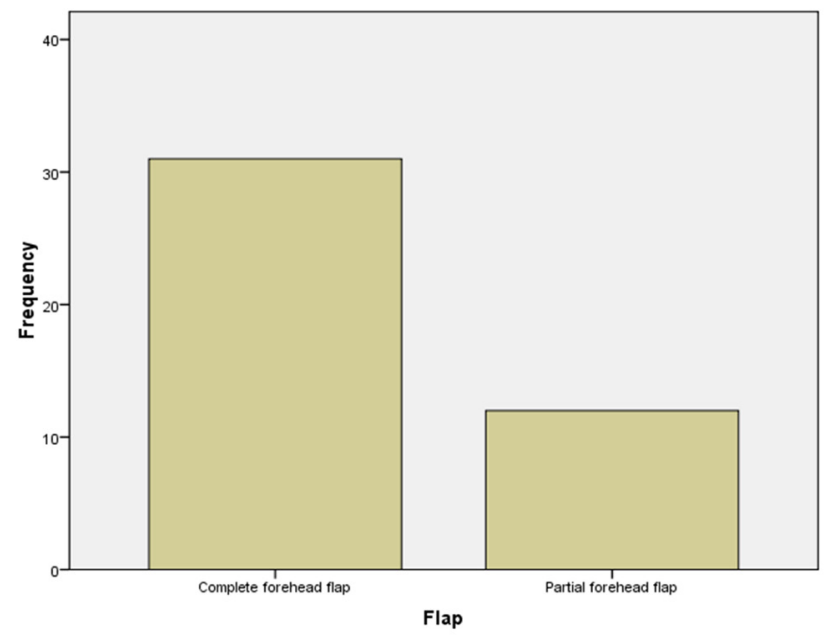

Figure 3: Types of forehead flap used

partial forehead flap was used in the remaining $12(27.9 \%)$ cases [Figure 3]. Immediate soft tissue reconstruction was performed in $7(16.3 \%)$ cases and all were secondary to tumor excision. The remaining $36(83.7 \%)$ patients had delayed reconstruction. Timing of flap division was documented only in 19 (44.2\%) of the 43 patients reviewed and this ranged from 20 to 65 days with a mean of $35.8 \pm 11.9$ days. Of these, 11 (57.9\%) had delayed flap division, 8 (42.1\%) had conventional flap division. No patient had early division [Table 2]. All flaps were divided under general anesthesia.

Of the 43 patients reviewed, 23 had documentation on the duration of hospital stay and this ranged from 19 to 146 days with a mean of $66.9 \pm 31.0$ days. Postoperative complications [Table 3] was observed in $8(18.6 \%)$ patients and consisted of failed flap in $2(25.0 \%)$ patients, tumor recurrence in reconstructed site in $2(25.0 \%)$ patients and tumor occurrence in forehead flap donor site in $1(12.5 \%)$ patient.

\section{DISCUSSION}

Axial pattern forehead flaps include both partial (such as median, para-median and lateral) and complete flaps. These flaps are 

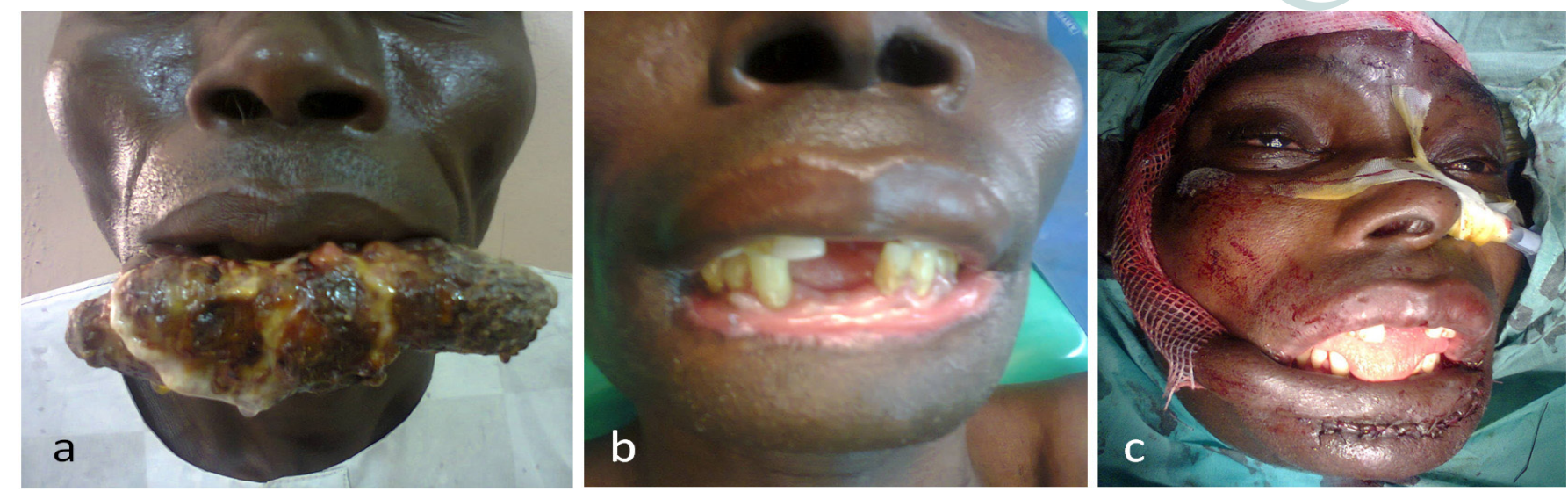

Figure 4: Forehead flap reconstruction of lower lip defect post squamous cell carcinoma excision. (a) Preoperative view; (b) delayed reconstruction to ensure tumour free margins; (c) forehead flap reconstruction

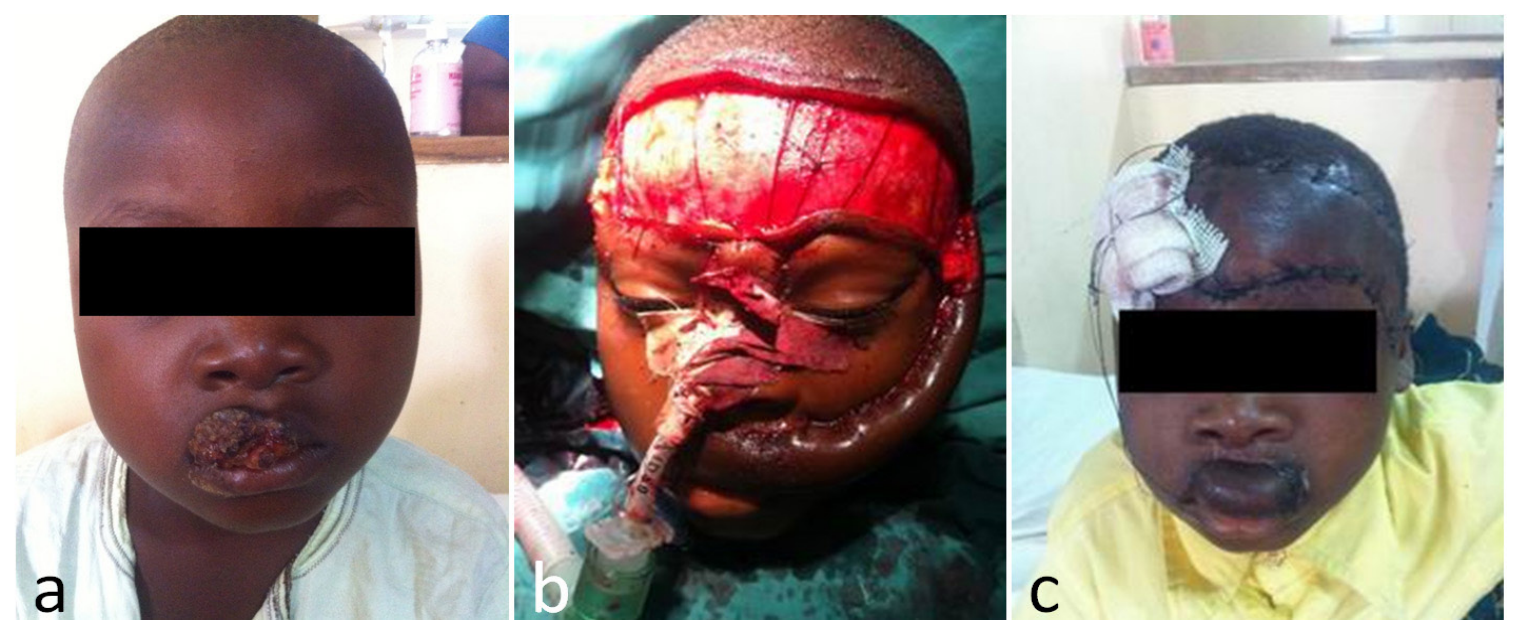

Figure 5: Forehead flap reconstruction of upper lip defect post squamous cell carcinoma excision. (a) Preoperative view; (b) immediate forehead flap reconstruction; (c) patient prior to flap debulking
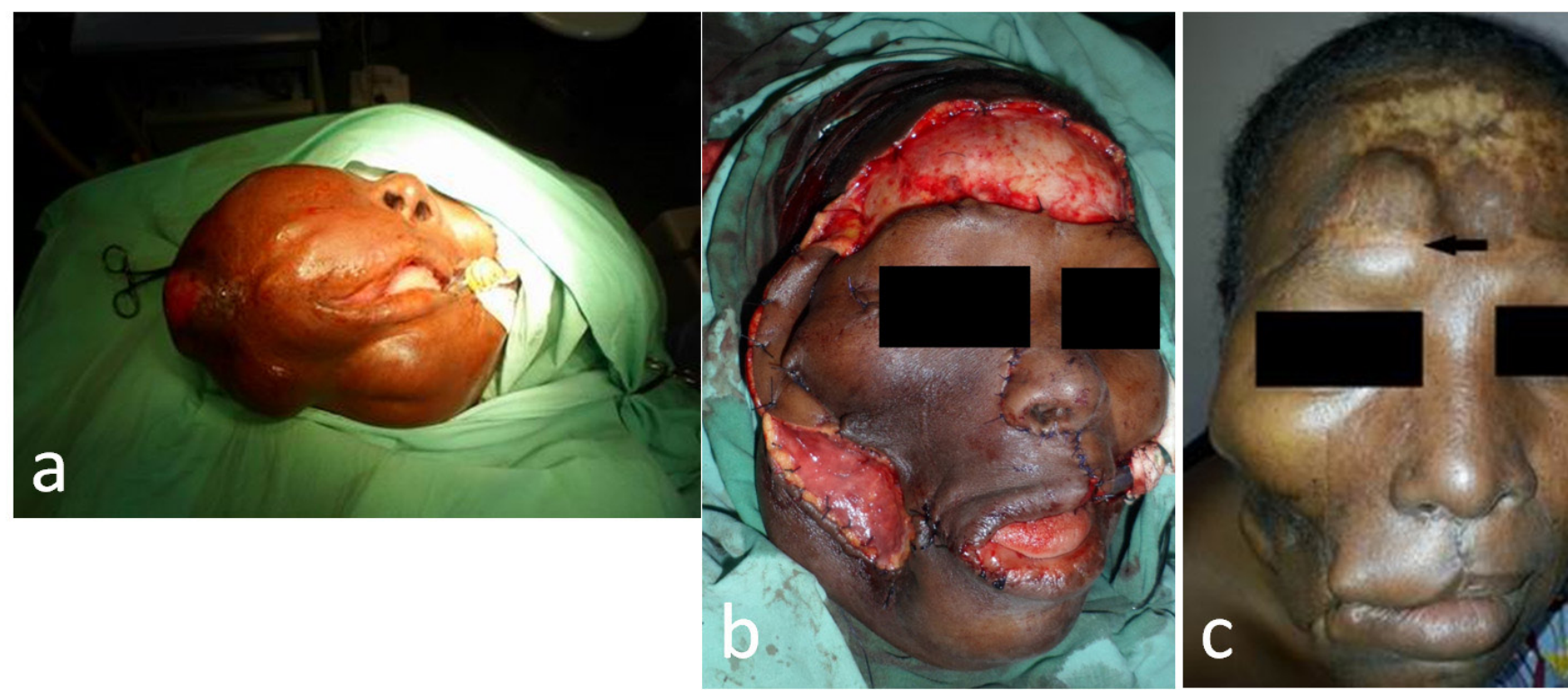

Figure 6: Tumour occurrence in forehead flap donor site. (a) Preoperative view of patient with mucoepidermoid carcinoma of the cheek; (b) tumour excision and immediate forehead flap reconstruction; (c) tumour occurrence in forehead (black arrow) 1 year postoperative

raised with the patient in supine position, thus eliminating the need to reposition and redrape patient as obtainable with other flaps such as the latissimus dorsi.

Majority $(72.1 \%)$ of patients reconstructed in the present study were males. Males in our environment are generally less concerned with aesthetics when compared to females. It is likely that these male patients were motivated as a result of functional limitations such as speech and feeding rather than aesthetics. The age of the patients ranged from 4-75 years 
and this highlight the wide range of patient age group that can be successfully reconstructed using this flap. Healing is usually excellent in children following use of forehead flap and this has been attributed to the non sebaceous quality of their forehead skin. ${ }^{[15]}$

Trauma (mainly road traffic crash) was the main aetiological factor for orofacial defect, followed by neoplasia. Delayed reconstruction was used in most patients and this may be related to the aetiological factors. Most road traffic crash soft tissue injuries in our environment present as class III or IV surgical wounds and require meticulous wound care to become clean before reconstruction can be undertaken. This fact has been highlighted in studies from this environment. ${ }^{[16,17]}$

Complete forehead flap was the most common type of flap used, accounting for $72.1 \%$ of all forehead flaps in our study. This is in contrast to other studies ${ }^{[18,19]}$ that reported partial forehead flaps as the most common type used. This difference may be related to the site [Table 3] and size of the soft tissue defect. About $57.4 \%$ of orofacial defects in our study were in the lower third and inferior half of the middle-third of the face [Figures 4 and 5]. Thus, the need for increased flap width and length to enable a wider arc of rotation in addition to adequate defect coverage favored our use of complete forehead flap. From our experience, the flap can be used to cover defects as low as the inferior border of the mandible and can provide tissue for both internal (mucosal) lining and external (skin) cover when folded along its long axis. The complete forehead flap is based on the frontal branch of the superficial temporal artery (FBSTA). The FBSTA enters the forehead at varying transverse levels at the lateral orbital rim vertical plane and anastomose with the supraorbital and supratrochlear arteries on one side, and the FBSTA on the contralateral side. However, in $74 \%$ of cases, the FBSTA entered the forehead at the junction between the middle and inferior transverse thirds of the forehead. ${ }^{[14]}$

Of the partial forehead flaps, the median forehead flap which is based on supratrochlear artery bilaterally and the angular artery, offers the shortest distance of rotation. In contrast, the paramedian flap which is based on the supratrochlear artery on one side with contributions from the angular and supraorbital artery (depending on the width of the flap) offers a wider arc of rotation and thus increased cover of the defect. ${ }^{[14]}$

With regard to the timing of flap division, majority of the cases had delayed flap division (greater than 28 days). This is in contrast to other reports ${ }^{[13,20]}$ in which the flap was divided at 3 weeks or less. Factors responsible for the long waiting period prior to flap division noted in this study include; inability of patients to pay for flap division procedure, inadequate operating slots and disruption of medical services by health workers as a result of industrial disputes. Traditionally, forehead flaps are divided 3 weeks post transfer. During this period, patient experience some discomfort such partial obstruction of vision or an inability to use prescribed eye glasses due to bulging of the flap trunk. ${ }^{[21]}$ To shorten this period, different technique both in animal models and human subjects have been suggested and these include ischemic preconditioning, use of hyberbaric oxygen, perfusion fluorometry, laser Doppler flowmetry and near-infrared laser angiography. ${ }^{[22-26]}$ Early division of forehead flaps as at 4-6 days has been documented with minimal complications. However, it is recommended that early flap division should not be undertaken in active smokers and in patients with bleeding disorders to avoid complications. ${ }^{[21,27]}$

Documented disadvantages of the forehead flap include facial disfiguring and bulkiness of flap. Complications noted in this study are shown in Table 3. Infective complications were observed only in patients who were reconstructed using complete forehead flap. This increased tendency for infection with complete forehead flap may be related to the large surface area of the flap exposed.

Total flap failure was recorded in 2 cases $(1$ complete and 1 partial forehead flap). Failure of the median forehead flap occurred post division despite a timing period of 36 days prior to division. It is likely that excessive pressure was applied to the distal part of the flap during division or the patient had some underlying systemic abnormalities. Tumor occurrence at the donor [Figure 6] site one year after complete forehead flap division was documented in 1 case with mucoepidermoid carcinoma. The main presentation was swelling in the region of the forehead tissue that was previously returned back to the donor site following flap division. This was confirmed histologically to be mucoepidermoid carcinoma. Occurrence of tumor in flap donor site has been previously documented in the pectoralis major myocutaneous and deltopectoral flap donor sites. ${ }^{[28,29]}$

To the best of our knowledge, this is the first report of tumor occurrence in the forehead flap donor site. Two mechanisms are possible: implantation of tumor cells in the donor site during flap raising, and invasion of the distal end of pedicle flap by residual tumor cells in the recipient site which are subsequently transferred to the donor site following flap division. The possibility of this occurrence without the knowledge of the surgeon is further increased by the absence of frozen section technique in our environment to determine tumor free margins. Measures to decrease this avoidable and devastating complication such as the use of different sets of gloves, gowns and instruments from those used for tumor excision have been highlighted in some studies. ${ }^{[30]}$ In addition, we recommend that where available, frozen section of the distal end of pedicle flaps should be obtained after flap division before returning it to the donor site. During follow-up review, attention should not be focused only on the recipient site; the flap donor site should also be regularly examined.

In conclusion, the forehead flap remains a reliable option in orofacial soft tissue defect reconstruction. It is easy to raise, can provide coverage for wide defects as far as the paramandibular region, it does not require patient repositioning and provides good textural, thickness and colour match when compared with the recipient site tissues.

\section{Financial support and sponsorship}

Nil.

\section{Conflicts of interest}

There are no conflicts of interest. 


\section{REFERENCES}

I. Ellis E III, Scott K.Assessment of patients with facial fractures. Emerg Med Clin North Am 2000; I 8:4 I I-48.

2. Aziz SR, Zichard VB, Borah G.A current therapy: complications associated with rigid internal fixation of facial fractures. Compend Contin Educ Dent 2005;26:565-7I.

3. De Sousa A. Psychological issues in acquired facial trauma. Indian J Plast Surg 2010;43:200-5.

4. Cawood Jl, Stoelinga PJW. International academy for oral and facial rehabilitation-consensus report. Int J Oral Maxillofac Surg 2006;35:195-8.

5. $\mathrm{Ng} \mathrm{W}$. Reconstructive options in head and neck surgery. Hong Kong Med Diary 2007; 12:14-6.

6. Janis JE, Kwon RK, Attinger CE. The New reconstructive ladder: modifications to the traditional model. Plast Reconstr Surg 20I ; I27:S20512.

7. Asamura S, Kakizaki H, Mori K, Matsunaga K, Wada M, Isogai N. The pectoralis major myocutaneous pedicled flap revisited. Surg Sci 20I 3;4:380 4.

8. Chim H, Salgado CJ, Seselgyte R, Wei FC, Mardini S. Principles of head and neck reconstruction: an algorithm to guide flap selection. Semin Plast Surg 2010;24:148-54

9. Hunt JP, Buchmann LO. The supraclavicular artery flap for lateral skull and scalp defects: effective and efficient alternative to free tissue transfer. $J$ Neurol Surg Rep 2014;75:e5-10.

10. Rinaldo A, Shaha AR, Wei WI, Silver CE, Ferlito A. Microvascular free flaps: a major advance in head and neck reconstruction. Acta Otolaryngol 2002; | 22:779-84.

II. Baliarsing AS, Thorat TS, Gupta A, Bhat U, Garg S, Bhattacharyya D. Flap selection in head and neck cancer reconstruction. Int J Otorhinolaryngol Clin 20I3;5:63-76.

12. Colletti G, Autelitano L, Tewfik K, Rabbiosi D, Biglioli F. Autonomized flaps in secondary head and neck reconstructions. Acta Otorhinolaryngol Ital 2012;32:329-35

13. Yavuzer R, Ayhan S, Cavusoglu T, Latifoglu O, Ozmen S. A workhorse for nasal reconstruction: the forehead flap. Gazi Med J 200 I; I 2:107-II.

14. Kleintjes WG. The vascular anatomy of the forehead related to forehead flaps and its application in plastic and reconstructive surgery. Dissertation presented for the degree of Doctor in Philosophy, Faculty of Health Sciences at the University of Stellenbosch, 2007.

15. Burget GC. Preliminary review of pediatric nasal reconstruction with detailed report of one case. Plast Reconstr Surg 2009; I 24:907-I8.
16. Akinyoola AL,Ako-Nai AK, Dosumu O,Aboderin AO, Kassim OO. Microbial isolates in early swabs of open musculoskeletal injuries. Niger Postgrad Med J 2006; |3:|76-8|.

17. Kigera JWM, Shamim M.Antibiotic prescription patterns in the management of open fractures at Mulago Hospital in Kampala. East Cent African J Surg 20I2;17:47-50.

18. Bhatt $Y$, Vyas K, Nakade D, Zade M. Reconstruction of nasal defects our three years experience. Indian J Otolaryngol Head Neck Surg 2006;58:5I-6.

19. Rao J, Deora H. Surgical excision with forehead flap as single modality treatment for basal cell cancer of central face: single institutional experience of 50 cases. J Skin Cancer 20I4;20I4:320792.

20. Shaikh MI, Rajput F, Khatoon S, Shaikh MA. Forehead flap for reconstruction of maxillofacial region defects. JLUMHS 2014;13:6I-6.

21. Somoano B, Kampp L, Gladstone HB. Accelerated takedown of the paramedian forehead flap at I week: indications, technique, and improving patient quality of life. J Am Acad Dermatol 20 I I;65:97-I05.

22. Halim AS, Kamal WS, Noor NM, Abdullah S. Effects of ischemic preconditioning of different intraoperative ischemic times of vascularized bone graft rabbit models. Arch Plast Surg 2013;40:687-96.

23. Richards L, Lineaweaver WC, Stile F, Zhang J, Zhang F. Effect of hyperbaric oxygen therapy on the tubed pedicle flap survival in a rat model. Ann Plast Surg 2003;50:5I-6.

24. Furnas DW, Lamb RC, Achauer BM, Turpin IM, Black KS. A pair of fiveday flaps: early division of distant pedicles after serial cross-clamping and observation with oximetry and fluorometry. Ann Plast Surg 1985; 15:262-7.

25. Cheng MH, Chen HC, Wei FC, See LC, Lee HY, Wang CJ. Combined ischemic preconditioning and laser doppler measurement for early division of pedicled groin flap. J Trauma 1999;47:89-95.

26. Liu DZ, Mathes DW, Zenn MR, Neligan PC. The application of indocyanine green fluorescence angiography in plastic surgery. J Reconstr Microsurg 20II;27:355-64.

27. White JB, Macht SD. Two-stage nasolabial flaps for facial reconstruction: revisiting the Three Week Rule for pedicle division. Laryngoscope 2010; 120:S109.

28. Vasu RC, Vijayakumar M, Sabitha K.S, Chris DA, Mahesh K, Jagadish S. Pectoralis major myocutaneous (PMMC) flap donor site recurrence in a case of buccal mucosal cancer: a case report. Int J Health Sci Res 2013;3:557.

29. Ashok BC, Cherian MT, Ashok H. Secondaries at deltopectoral flap donor site. Indian J Cancer 2002;39: I49-50.

30. Robbins KT, Woodson GE. Chest wall metastasis as a complication of myocutaneous flap reconstruction.J Otolaryngol 1984;3:13-4. 